\title{
LAS INVESTIGACIONES SOBRE EL MERCADO NEGRO DE PRODUCTOS AGRARIOS EN LA POSTGUERRA: SITUACION ACTUAL Y PERSPECTIVAS*
}

\author{
CARLOS BARCIELA LOPEZ \\ Universidad de Alicante
}

El presente trabajo pretende, por una parte, destacar la extraordinaria importancia que alcanzó el mercado negro de productos agrarios en la postguerra y sus repercusiones sobre los distintos grupos sociales. Por otra, se intenta resaltar la labor de ocultación y manipulación realizada por los responsables de las estadísticas agrarias, así como la insuficiencia de las investigaciones llevadas a cabo para subsanar estos problemas. Finalmente, se intenta mostrar cuáles son actualmente las tareas más urgentes a realizar y las posibles vías para desarrollarlas.

El mercado negro de productos agrarios en la postguerra, 1939-1953

En España, a partir de 1939, y como es sobradamente conocido, se desarrolló un amplio mercado negro que afectó a todo tipo de materias primas y productos básicos. Especial importancia alcanzó el mercado negro de productos alimenticios, que perduró mientras se mantuvo el régimen de racionamiento y el sistema de intervención en la agricultura, cuyo principal instrumento fue la requisa de productos a los campesinos a precios de tasa.

A pesar de la extraordinaria importancia del mercado negro de productos agrarios y de la gravedad de sus consecuencias, no son muchas las investigaciones que se han realizado sobre el tema. La presente nota intenta mostrar cuál es el estado actual de nuestros conocimientos sobre el fenómeno del «estraperlo» de productos agrarios en los años cuarenta, sobre las consecuencias del mismo y sobre las necesidades y limitaciones de posibles futuras investigaciones. En mi opinión, tras la aportación - pionera, aunque limitada en lo relativo a los resultados - realizada por Francisco Alburquerque en su tesis

* Una primera versión de este trabajo fue expuesta en el Salón de Actos de la Facultad de Ciencias Económicas y Empresariales de la Universidad de Valencia, el día 10 de noviembre de 1984, en el marco del Coloquio España bajo el franquismo. Quiero agradecer a José Manuel Naredo sus importantes sugerencias y comentarios que han permitido mejorar aquella primera versión. 
doctoral, las investigaciones más relevantes realizadas sobre el tema han sido las de José Manuel Naredo, Carmen Gutiérrez del Castillo, Aurelio García González y Carlos Barciela López. La monografía de J. M. Naredo enfoca e] problema con carácter general, no perdiendo de vista ninguno de los aspectos relevantes del mercado negro, estudiando tanto las cantidades como los pre. cios de los diversos productos agrícolas «estraperlados» en las grandes fincas del sur de España. En cuanto a las fuentes de información, J. M. Naredo utilizó fuentes de carácter privado, concretamente las propias contabilidades de las fincas objeto de estudio. El planteamiento teórico del trabajo de Naredo constituye un modelo que debería ser utilizado para emprender nuevas investigaciones. El trabajo de Carmen Gutiérrez tiene como objeto el estudio del «estraperlo» de aceite de oliva en el período 1940-1944. Carmen Gutiérrez ha utilizado en su investigación esencialmente fuentes de carácter oficial, especialmente de la Comisaría General de Abastecimientos y Transportes. Finalmente, los trabajos de Carlos Barciela y Aurelio García González están centrados en torno al principal producto objeto de «estraperlow, el trigo, durante el período 1939-1953. Las fuentes utilizadas han sido, en este último caso, también fundamentalmente oficiales, del Servicio Nacional del Trigo y, especialmente, del Banco de España.

Los resultados de este grupo de investigaciones podrían sintetizarse de la forma siguiente:

a) En relación a las cantidades «estraperladas» destaca, en todos los trabajos, la extraordinaria importancia que alcanzaron, hasta el punto de que el mercado negro superó - caso del trigo- o estuvo muy cercano -caso del aceite- al propio mercado oficial.

b) Los precios a los que se vendieron los productos «estraperlados» superaron, por término medio, entre 2 y 3 veces los precios oficiales de tasa'.

c) La calidad de los productos «estraperlados», dado el carácter ilegal del mercado y la multitud de demandantes, se deterioró notablemente. Los consumidores adquirieron, en general, productos de mala calidad, sin ninguna garantía y a precios muy elevados.

d) El ocultamiento de parte de la cosecha para su posterior comercialización en el mercado negro se tradujo en una infravaloración, por parte del Ministerio de Agricultura, de los volúmenes de producción agraria. Posteriormente, ya en los años cincuenta, se procedió, en algunos casos, por parte de la Sección de Estadística del Ministerio de Agricultura, a una revisión al alza de las producciones de trigo, avena, cebada y centeno, aunque no se hizo lo

\footnotetext{
${ }^{1}$ Un análisis teórico del mercado negro puede verse en C. Barciela (1983 b).
} 
mismo para otros productos agrarios que fueron también objeto de «estraperlow ${ }^{2}$.

e) Puede hablarse, pues, de un fracaso del sistema de intervención en la agricultura practicado por el «Nuevo Estadow. Los agricultores rechazaron los cauces oficiales y, a pesar del riesgo (que, dicho sea de paso, no afectaba a todos los «estraperlistas» por igual) que implicaba la participación en el mercado negro, éste se vio más concurrido que el propio mercado oficial. Los organismos interventores, Servicio Nacional del Trigo y Comisaría General de Abastecimientos y Transportes, no comercializaron los productos y las cantidades que debían, teóricamente, comercializar y los precios oficiales de tasa fueron sistemáticamente vulnerados.

f) Debe destacarse que el sistema de intervención, a pesar de su aparente objetividad, no afectó ni a todos los productos ni a todos los agricultores por igual. Respecto a los productos, cabe advertir que el mayor control ejercido sobre el trigo hizo que sus porcentajes de ocultación fueran menores que los de otros productos en los que la Administración ofrecía mayor permisividad (por ejemplo, leguminosas, otros cereales, etc.), aunque en términos absolutos el trigo fuera el producto rey del kestraperlow. En lo que concierne a los agricultores, las entregas obligatorias a bajos precios de tasa fueron, normalmente, mejor satisfechas por los pequeños campesinos, indefensos ante los funcionarios de los organismos de intervención. Sin embargo, los agricultores grandes y medianos contaron con todo lo necesario para poder participar en el mercado negro: excedentes, lugares para ocultar parte o toda la cosecha, medios de transporte ( $o$, en su defecto, capacidad financiera para alquilarlos), conocimiento del mercado (fabricantes, intermediarios urbanos) y, lo más importante, la impunidad política que les proporcionaba el formar parte del bando victorioso en la contienda civil. No obstante, la amplia casuística que caracteriza el fenómeno del kestraperlon dificulta enormemente cualquier intento de generalización por zonas y tamaño de las explotaciones agrarias.

g) La intervención proporcionó dos mecanismos de acumulación. Por una parte, se logró proporcionar un nivel mínimo de racionamiento a bajos precios a los obreros industriales, lo que hizo soportable la perdida de poder adquisitivo de los salarios experimentada en los años cuarenta, con cargo al sector agrario. Por otra parte, la intervención estatal tuvo un efecto muy distinto entre aquellos agricultores que acumularon importantes beneficios, gracias a su participación en el mercado negro o a las concesiones de abonos y

${ }^{2}$ Puede verse un análisis crítico de las revisiones de estadísticas agrarias hechas por la Sección de Estadística del Ministerio de Agricultura en C. Barciela, «Las estadísticas agrarias en España 1936-1980* (en curso de publicación en obra colectiva dirigida por el profesor A. Carreras. 
maquinaria, y aquellos otros que no lo hicieron o lo hicieron más moderadamente. Esto se tradujo, en muchas ocasiones, en reajustes de la propiedad de la tierra, apareciendo en aquella época nuevos apellidos en el grupo de los grandes propietarios, fruto de fortunas acumuladas en los años cuarenta (hay que recordar que el «estraperlo" de una cosecha, en condiciones favorables, arrojaba un beneficio por hectárea similar al precio de la tierra).

b) En otro orden de cosas, podemos considerar como una consecuencia más del mercado negro la mala calidad de las estadísticas agrarias oficiales relativas a los años 1939-1953. En realidad, siendo más precisos, no deberíamos achacar esta falta de calidad a la existencia de un mercado negro; debemos, más bièn, responsabilizar de ello a las autoridades, que intentaron negar oficialmente el fenómeno del «estraperlo»... a base de no reconocerlo estadísticamente. Se puede afirmar que, como consecuencia de esta actitud, las estadísticas oficiales de precios de los productos agrarios, de valores de las producciones, de renta agraria y, como consecuencia, de la renta nacional están notablemente infravaloradas. La importancia del fenómeno es indudable y sorprende cómo todavía hoy el Ministerio de Agricultura sigue publicando unas series (que muchos investigadores siguen utilizando) de cantidades, precios y valoraciones que tienen muy poco que ver con la realidad. La única revisión que se ha llevado a cabo en este sentido, si no estoy equivocado, ha sido la realizada por Aurelio García y Carlos Barciela (1983) para los precios y valores de la producción triguera.

La última de las cuestiones que quería comentar en esta breve nota es la relativa a las lagunas existentes en la investigación y las posibilidades de superarlas. Los aspectos no estudiados hasta el momento son muchos. Excepto sobre el trigo y sobre el aceite, y para este último producto sólo en el subperíodo 1940-1944, no se han realizado investigaciones monográficas sobre el mercado negro de ningún otro producto agrario. Como mínimo, para poder tener una visión general del problema que venimos tratando, sería necesario: completar el estudio del aceite, investigar algún cereal más (centeno, cebada, arroz o maiz) y analizar lo que aconteció con el comercio de las principales leguminosas. Simultáneamente sería necesario investigar lo que sucedió con los productos ganaderos y forestales.

Las posibilidades de realizar estas investigaciones no aparecen, lamentablemente, muy claras, principalmente por la falta de documentación. Conforme al resultado de mis averiguaciones, el SENPA (heredero del antiguo SNT) no dispone de información sobre el "estraperlo" de otros productos distintos del trigo. Resulta muy extraña esta carencia, dado que el SNT intervino no sólo el trigo, sino la totalidad de los cereales y leguminosas. Oficialmente, sin embargo, no existe información. En mi opinión, no obstante, mientras el ar- 
chivo del SENPA permanezca cerrado a los investigadores, no podemos tener certeza sobre la existencia o no de documentación sobre este tema. Sería también posible que la documentación hubiera sido destruida, práctica habitual en el SENPA.

En relación con la Comisaría General de Abastecimientos y Transportes (organismo que intervino una amplia variedad de productos agrícolas y ganaderos), hay que señalar la implacable destrucción de todo documento que pudiera proporcionar información de su gestión durante el período franquista. Es posible, dada la particular eficacia demostrada por la CGAT en la destrucción de documentos, que nunca se pueda llegar a realizar un estudio completo de la actividad de este organismo de amargo recuerdo para muchos españoles.

Las dificultades no son, a pesar de todo, insalvables, y el investigador ha de poner en juego su ingenio. José Manuel Naredo, mediante el estudio de contabilidades privadas, y Aurelio García y Carlos Barciela, mediante el estudio de contabilidades de fabricantes de harinas, han mostrado dos caminos, alternativos a las fuentes oficiales, muy fructíferos para el estudio del problema.

Finalmente, quiero señalar que en la actualidad se están llevando a cabo nuevas investigaciones sobre el fenómeno del «estraperlo». Carmen Gutiérrez prosigue con sus trabajos sobre el aceite; Daniel Criach, dirigido por José Fontana, ha comenzado recientemente un estudio sobre el «estraperlo» de productos agrarios en Cataluña, y José Pujol tiene, prácticamente, concluido un excelente trabajo sobre el mercado negro en base al estudio de contabilidades de fincas privadas.

\section{BIBLIOGRAFIA}

Alburquerque, Francisco: Investigación acerca del marco institucional en el que se configuró el sistema de racionamiento de alimentos a partir de la última guerra civil en España, tesis doctoral leída en la Facultad de Ciencias Económicas y Empresariales de la Universidad Complutense de Madrid.

Barciela, Carlos (1981): «El "estraperlo" de trigo en la postguerra", Moneda y Crédito, 151 , pp. $17-37$.

- (1983 a): «Producción y política cerealista durante la guerra civil española, 1936-1939», en G. Anes, L. A. Rojo y P. Tedde (eds.): Historia Económica y Pensamiento Social, Madrid, Alianza Universidad-Banco de España.

- (1983 b): «Intervencionismo y crecimiento agrario en España, 1939-1971» (ponencia presentada en el Seminario de Historia Económica Cuantitativa, celebrado en la Fundación Ortega y Gasset).

Barciela, Carlos, y García Gonzílez, Aurelio (1983): «Un análisis crítico de las series estadísticas de los precios del trigo entre 1937 y 1980», Agricultura y Sociedad, 29, Pp. 69-151.

GuTiÉRrez, Carmen (1983): «Una estimación del mercado negro de aceite de oliva en la postguerra españolax, Agricultura y Sociedad, 29, pp. 153-173.

NAredo, José Manuel (1981): "La incidencia del "estraperlo" en la economía de las grandes fincas del sur de España*, Agricultura y Sociedad, 19, pp. 81-128. 